\title{
LA PATENTABILIDAD DE LA MEDICINA TRADICIONAL PALENQUERA: ANTÍDOTO JURÍDICO PARA EL TLC CON ESTADOS UNIDOS ${ }^{1}$
}

Patentability of Traditional Medicine of Palenque: Legal Antidote for the TPA with the United States ${ }^{1}$

Chavelly Jiménez Castellanos $^{2}$

Fecha de Recepción: Mayo 5 de 2014

Fecha de Aceptación: Mayo 12 de 2014

Sumario: 1. Introducción, Metodología, Justificación; 2. Propiedad intelectual y sus fundamentos jurídicos, a. Definición de propiedad intelectual, b. Normatividad general de la propiedad intelectual; 3. Las patentes, a. La patente farmacéutica, b. Conocimientos tradicionales y patentes, c. Patentes en el Tratado de Libre Comercio con Estados Unidos, d. Medicina tradicional de San Basilio de Palenque;

4. Conclusiones; 5. Referencias bibliográficas.

\footnotetext{
${ }^{1}$ Este artículo da cuenta del trabajo adelantado en el marco del proyecto de investigación de la línea propiedad intelectual del Grupo de Investigación Conflicto y Sociedad de la Universidad de Cartagena llevado a cabo en la población de San Basilio de Palenque, (Bolívar) en el año 2013, forma parte del informe final, mucho más amplio, llevada a cabo por la autora, cuyos intereses investigativos y profesionales giran alrededor de la propiedad intelectual y que también fue tema de su especialización en derecho comercial.

${ }^{2}$ Abogada de la Universidad de Cartagena, Especialista en Derecho Comercial de la Universidad Libre de Colombia, abogada litigante. Docente e investigadora en temas de propiedad intelectual y conocimientos tradicionales. Miembro del Grupo de Investigación Conflicto y Sociedad de la Universidad de Cartagena, Categoría A COLCIENCIAS. chavellyjimenezc@gmail.com
} 


\title{
COMO SE CITA ESTE ARTÍCULO (APA 6)
}

Jiménez Castellanos, C. (2014) La Patentabilidad de la Medicina Tradicional Palenquera: Antídoto Jurídico para el TLC con Estados Unidos. (Y. Carrillo De la rosa, Ed.) Revista Jurídica Mario Alario D'Filippo, VI (12), pág. 71-86

\section{RESUMEN}

Este artículo plantea un análisis jurídico de cómo la firma del Acuerdo de Promoción Comercial entre Colombia y Estados Unidos, que rige desde el 15 de mayo de 2012, arriesga la medicina tradicional de San Basilio de Palenque. En su tenor se aduce que lo pactado vulnera las garantías existentes para los conocimientos tradicionales, contenidas en instrumentos como el Convenio de Diversidad Biológica, las Decisiones 391 de 1996 y 486 del 2000 de la Comunidad Andina de Naciones, y los ADPIC. Esta situación abre las puertas para que las empresas farmacéuticas norteamericanas patenten moléculas químicas de plantas utilizadas en la medicina tradicional palenquera, sin beneficios económicos equitativos para esta comunidad.

\begin{abstract}
This article presents a legal analysis of how the signing of the Trade Promotion Agreement between Colombia and the United States, which runs from May 15, 2012, risking the traditional medicine of San Basilio de Palenque. In his tenor it argues that the agreement violates existing guarantees for traditional knowledge, contained in instruments such as the Convention on Biological Diversity, Decisions 391 of 1996 and 486 of 2000 of the Andean Community of Nations, and TRIPS. This opens the door for US pharmaceutical companies patented chemical molecules of plants used in traditional medicine palenquera without equitable economic benefits for this community.
\end{abstract}

\section{PALABRAS CLAVE}

TLC, propiedad industrial, patente, medicina tradicional, San Basilio de Palenque.

\section{KEYWORDS}

Free Trade Agreement, industrial property, patent, traditional medicine. 


\section{INTRODUCCIÓN}

Culminada la Guerra Fría, el liberalismo económico se impuso inevitablemente en el mundo occidental. Los Estados que ya habían incursionado en la apertura de sus mercados, se vieron abocados a profundizar el modelo y los que no, debieron empezar rápidamente a adaptar sus leyes internas para hacer de esto una realidad. La creación de la Organización Mundial de Comercio (OMC), posibilitó que los países, haciendo algunas concesiones a su soberanía, pudiesen unirse económicamente en diferentes mecanismos, en aras de aumentar su competitividad a nivel mundial y beneficiar a exportadores, importadores y consumidores. Uno de estos modos ideados fueron los Tratados de Libre Comercio -TLC-. Los TLC son acuerdos mediante los cuales dos o más países reglamentan de manera comprehensiva sus relaciones comerciales, con el fin de incrementar sus flujos de comercio e inversión y, por esa vía, su nivel de desarrollo económico y social.

La Constitución Colombiana de 1991 dio pie a la liberalización económica y permitió la entrada de Colombia a la Organización Mundial de Comercio creada en 1995, que a su vez constituyó el sistema multilateral de comercio. Aquí se incluyeron los distintos instrumentos regionales de liberalización económica que podía utilizar los Estados entre sí, para generar crecimiento económico, aumentar el empleo y la calidad de vida, tales como el Sistema de Preferencias, las Áreas de Libre Comercio o Tratados de Libre Comercio, la Unión Aduanera, el Mercado Común y otras formas más avanzadas. Así las cosas, se han firmado sendos acuerdos de libre comercio, entre ellos con los Estados Unidos de América, sin embargo aún queda la preocupación relacionada con el otorgamiento de patentes de manera particular la que tiene que ver con nuestra medicina ancestral, por ello este trabajo da cuenta de los peligros que podría enfrentar la medicina tradicional Palenquera frente al TLC con Estados Unidos. El riesgo de que el principio activo -la molécula química que tiene efectos curativos, paliativos o cosméticos- de sus plantas medicinales pueda ser irresponsablemente patentada y la comunidad no tenga cabida en las ganancias de manera equitativa o en un caso extremo, sean despojados de su conocimiento como ha ocurrido en otras partes del mundo.

\section{METOdOLOGÍA}

La presente es una investigación socio jurídica de carácter cualitativo, que combina el análisis de información primaria y secundaria, respecto a la primera se aplicaron entrevistas a informantes clave entre otros a licenciados en etno educación y médicos tradicionales en el pueblo de Palenque(Bolívar) y al Consejo Comunitario Mankamana. El informe se inicia con la justificación del tema, luego se analizará lo concerniente a la propiedad intelectual, fundamentos jurídicos y normatividad en general, luego se pasa al análisis de las patentes y dentro de estas a las patentes farmacéuticas, posteriormente al tema de las patentes en el marco del TLC y por último a la medicina tradicional en Palenque y sus implicaciones con respecto a este acuerdo bilateral.

\section{JUSTIFICACIÓN}

El Acuerdo de Promoción Comercial entre Colombia y Estados Unidos, más conocido como TLC, sus cartas adjuntas y sus entendimientos fueron firmados el 22 de noviembre del 2006, en la capital 
estadounidense, Washington. La ley que incorporó el tratado al corpus legislativo colombiano fue la 1143 del 2007. La Sentencia C-750 del 2008 de la Corte Constitucional la declaró exequible. El Protocolo Modificatorio del tratado entró a la legislación colombiana bajo la Ley 1166 del 2007 y fue declarado constitucional por la Sentencia C-751 del 2008. El 12 de octubre del 2011, fue aprobado por el Congreso norteamericano y fue sancionado por el presidente Barack Obama el 21 de octubre del mismo año. En la Cumbre de las Américas que se llevó a cabo en la ciudad de Cartagena en abril del 2011, se realizó el canje de notas y el día 15 de mayo del 2012, cuando se promulgó el "Acuerdo de Promoción Comercial entre la República de Colombia y los Estados Unidos de América", sus Cartas adjuntas y sus entendimientos, entró en vigencia.

EI TLC comprende 23 capítulos, divididos entre lo referente a la compatibilidad jurídica del TLC con la Comunidad Andina de Naciones, la desgravación de los artículos, el acceso a los mercados de ambos países y asuntos trasversales como los derechos laborales, la competencia y la propiedad intelectual. Es precisamente la redacción de este último capítulo lo que nos interroga.

El Capítulo XVI del Tratado de Libre Comercio, establece lo pertinente respecto a la propiedad intelectual. Específicamente el Artículo 16.9 regula lo referente a las patentes. El inciso 1 de dicho artículo, especifica que se patentará en todos los campos de la tecnología, siempre y cuando el invento tenga capacidad inventiva y aplicación industrial. En el inciso 2 , se establece expresamente que a pesar de lo señalado en el ADPIC (Acuerdo de la Organización Mundial de Comercio sobre asuntos de la Propiedad Intelectual),- Artículos 27.2 y 27.3 del ADPIC que prohíben la patentabilidad de las plantas y los animales con excepción de los microorganismos- se podrán patentar plantas y estas patentes no pueden ser menoscabadas por ninguna razón. En el inciso 3 se dice que serán excepcionales las razones por las cuáles se puedan limitar los derechos que confiere una patente y por ningún motivo, estas limitaciones pueden ir en contra de la normal explotación de la patente, ni perjudicar los derechos del titular de la patente, ni de los terceros.

La riqueza lingüística y sociocultural de Colombia es inigualable. Existen desde la Guajira hasta la Amazonia, comunidades tradicionales que aún conservan sus prácticas intactas, a pesar del devastador paso del "hombre blanco". Para el caso concreto de este trabajo, fue analizada la población de San Basilio de Palenque, paradigma de la lucha afroamericana, considerada el primer pueblo libre de América. El Tratado de Libre Comercio con Estados Unidos, tal y como quedó redactado, es una bomba de tiempo para sus conocimientos milenarios, específicamente para su medicina tradicional.

San Basilio de Palenque es un corregimiento adscrito al municipio de Mahates, ubicado a $70 \mathrm{kms}$ de la ciudad de Cartagena de Indias (Colombia). Declarado por la Unesco Patrimonio Intangible de la Humanidad en el año 2003. Emplazado en uno de los valles de los Montes de María, a $100 \mathrm{mts}$ sobre el nivel del mar. Fundado en el Siglo XVI, liderado por Benkos Bioho quien lideró los negros cimarrones fugados de sus amos españoles en el período colonial. La tradición lo considera el primer pueblo libre de América. Símbolo de la resistencia hacia la Corona Española y emblema de la herencia africana. Palenque tiene plena conciencia étnica, sentido de pertenencia. Son poseedores de la única lengua criolla con base léxica española, una compleja y peculiar organización social -los kuagros-, la conservación de la ceremonia fúnebre africana, el lumbalú, herederos de una tradición 
artística, estética y espirituales de su "madre patria" africana. (Ministerio de Cultura \& Institutito Colombiano de antropología e historia, 2002)

Uno de los elementos configuradores de su cultura, es el uso de la medicina tradicional para curar diversas enfermedades, tanto somáticas como espirituales. Los palenqueros mantienen y practican en su seno, toda clase de rituales médicos-religiosos, basados en plantas, animales y rezos con los cuáles ellos tratan enfermedades respiratorias, renales, musculares, entre otras. Son prácticas rituales milenarias, trasmitidas generacionalmente en línea recta, que no tienen propietario determinado, sino que pertenecen a toda la comunidad y que a diferencia de la medicina occidental no solo requiere para su ejercicio, aptitud cognitiva, sino ciertas cualidades morales.

Dentro del Capítulo XVI de la Propiedad Intelectual del TLC, hay un documento adjunto llamado Entendimiento sobre Biodiversidad y Conocimientos tradicionales, en el que se reconoce el consentimiento informado y la distribución equitativa de beneficios en los negocios comerciales donde se involucren conocimientos tradicionales. Sin embargo, esto se deja al arbitrio de los contratantes, desconociendo por completo instrumentos internacionales garantistas como el Convenio de Diversidad Biológica y la Decisión 391 de 1996 de la Comunidad Andina de Naciones, que protegen la desigualdad e indefensión en que se encuentran las comunidades en relación con las grandes empresas farmacéuticas y que le da pie a una parte de la doctrina, para proponer el contrato de How Know sui generis, asimilando los especiales conocimientos étnicos a secretos industriales, abriendo la puerta para la obtención de regalías equitativas que satisfagan a todas las partes.

Los dos últimos ítems del Entendimiento prescriben que cada parte, para verificar la condición de novedad de la patente, suministrará "bases de datos públicamente accesibles que contengan información relevante" y una oportunidad de comunicar por escrito el estado de la técnica de lo que se quiere patentar. Estas son condiciones que van en contra de las características socioculturales palenqueras, que están por fuera de su orden epistemológico, ya que nunca han inventariado sus conocimientos porque están basados en la oralidad y en la trasmisión solidaria y desinteresada entre padres e hijos y además, no manejan el lenguaje de la farmacopea occidental, hecho que los coloca en inequitativas condiciones de negociación con los grandes emporios corporativos.

Lo descrito denota el inminente peligro en que se encuentra la medicina tradicional Palenquera frente al TLC con Estados Unidos. El riesgo de que el principio activo-la molécula química que tiene efectos curativos, paliativos o cosméticos- de sus plantas medicinales pueda ser irresponsablemente patentada y la comunidad no tenga cabida en las ganancias de manera equitativa o peor, sean despojados inescrupulosamente de su conocimiento, tal y como ha ocurrido en otras partes del mundo. Vandana Shiva, la reconocida activista hindú, dijo en su obra Proteger o Expoliar: los derechos de la propiedad intelectual, "Así en la actualidad, las empresas, los laboratorios comerciales, las universidades, los investigadores y, muy en especial, los gobiernos, parecen estar inmersos en un "juego depredador" en el que se realizan fuertes apuestas para acumular patentes que puedan ser vendidas por miles de millones de dólares" (Shiva, 2002). A continuación, algunos ejemplos ilustrativos que trae la Guía de Información y de Movilización frente 
a la apropiación ilegitima de los recursos biológicos y los conocimientos tradicionales. (Colectivo por una Alternativa a la Biopiratería, 2010)

El Neem es un árbol que hace parte de los colectivos tradicionales hindúes. Es utilizado como biopesticida, calefactor natural y crema facial. En 1994, la empresa, norteamericana W.R Grace consiguió la patente del Neem como agente hidrófobo para combatir las infecciones vegetales. Un árbol, utilizado durante 4500 años, logró ser monopolizado durante una década por una empresa apoyada por la Secretaría de Agricultura de Nueva York. En el 2001, por la gran presión pública al respecto, la patente fue anulada. Otro caso en la misma línea del Neem, es el Sacha Inchi, que son unas almendras con alta concentración de ácidos grasos, usadas milenariamente en la selva amazónica peruana para fines cosméticos. En el 2006, la empresa Greentech patenta ante la Oficina de la Propiedad Industrial francesa, el aceite de Sacha Inchi para el cuidado capilar y cutáneo y quedan registrados como sus "inventores". Gracias a la acción de los activistas franceses y peruanos en contra de la biopiratería, fue posible anular este derecho.

La misma guía que venimos comentando, se refiere a la flor originaria del archipiélago del Océano Índico, Las Comores, Ilamada por los nativos Ylang Ylang, es famosa por su esencia que sirve para la elaboración de perfumes. Empresas extranjeras, Ilegan a esas tierras, compran a muy bajo precio el producto y se enriquecen, mientras que los nativos, tradicionales productores, se eternizan en condiciones de pobreza.

El geranio sudafricano, el Pelargonium es utilizado con fines curativos y durante mucho tiempo estuvo patentado por la empresa alemana Schwabe. Esta firma farmacéutica, no respetó el consentimiento previo e informado que prevé el Convenio de Diversidad Biológica, ni tampoco el requisito de la novedad, motivos por las cuáles la patente fue anulada.

Sin lugar a dudas, el paradigma de la incorrecta utilización de los conocimientos tradicionales, es la ayahuasca. Una de las plantas más paradigmáticas de la Amazonia peruana, conocida desde tiempos inmemoriales por 72 tribus indígenas de la zona, considerada por los expertos de la salud mental "el mayor antidepresivo del mundo", fue patentada durante muchos años por la Plant Medicine Corporation, desde mediados de los años 80 . La patente solo logró ser anulada por la presión internacional producida en noviembre del 2003. Incluso, rumores locales hablan de misteriosos homicidios a chamanes por sus enfrentamientos a las farmacéuticas ${ }^{3}$.

Referirse a los riesgos del Tratado de Libre Comercio con Estados Unidos en relación a la medicina tradicional palenquera, no es un asunto especulativo. Es una preocupación legítima, jurídica y de paso ética, frente a un flagelo por el que ya han pasado otras comunidades a nivel mundial. Por tal razón, este artículo pretender demostrar la pertinencia para la comunidad de San Basilio de Palenque del patentamiento de algunas de sus fórmulas medicinales, así no sea lo más acorde con su cosmovisión. Además de recomendar un inventario público de fórmulas medicinales, en aras de garantizar de contrarrestar la "falta de novedad" que suele ser alegada en estos casos. Para lograr el fin propuesto, se partirá de la teoría general de la propiedad intelectual, aterrizando en la

${ }^{3}$ Ver más en http://www.perspectivaciudadana.com/contenido.php?itemid=5649 el 8 de agosto del 2013 a las 11:03 p.m 
propiedad industrial, especificamente en las patentes que es el mecanismo por el cual se protege la invención de medicamentos. Posteriormente se realizará un adentramiento en las características de los conocimientos tradicionales, se describirá como quedó la situación de dichos conocimientos en el TLC firmado entre Colombia y Estados Unidos y finalmente se mostrará una receta medicinal palenquera potencialmente afectada.

Son muy pocos los trabajos académicos en Colombia sobre la incidencia de los Tratados de Libre Comercio sobre el manejo de la biodiversidad. El objetivo es que esta investigación sea punta de lanza para que los estamentos sociales, políticos y académicos empiecen a indagarse, para que se ven obligados a actuar proactivamente en favor del tema.

\section{PROPIEDAD INTELECTUAL Y SUS FUNDAMENTOS JURÍDICOS DEFINICIÓN DE PROPIEDAD INTELECTUAL}

Según la Organización Mundial de la Propiedad Intelectual (OMPI), la propiedad intelectual tiene que ver con la creaciones de la mente, las invenciones, las obras literarias y artísticas, los símbolos, los nombres, las imágenes y los dibujos y modelos utilizados en el comercio. La propiedad intelectual se divide en dos categorías: la propiedad industrial, que incluye las invenciones, patentes, marcas, dibujos y modelos industriales e indicaciones geográficas de procedencias; y el derecho de autor, que abarca las obras literarias y artísticas, tales como los poemas, las novelas y las obras de teatro, las películas, las obras musicales, las obras de artes, tales como los dibujos, pinturas, fotografías, esculturas y los diseños arquitectónicos.

Para el caso específico de este artículo, se tratará lo relacionado con la propiedad industrial, que es donde entra la medicina tradicional palenquera potencialmente patentable por las farmacéuticas norteamericanas.

\section{a. NORMATIVIDAD GENERAL DE LA PROPIEDAD INDUSTRIAL}

A continuación haremos un breve recorrido por las normas de propiedad industrial que son pertinentes para este artículo de investigación.

El Convenio de París para la protección de la Propiedad Industrial, del 20 de marzo de 1883, del que hacen parte 85 países y ratificado por Colombia por la Ley 178 de 1994, es el principal cuerpo normativo de propiedad industrial en el mundo. Regula la propiedad industrial de manera amplia, en lo que respecta a invenciones, marcas, patentes, diseños industriales, nombres comerciales, denominaciones geográficas y competencia desleal. Fue establecido con el propósito de que los titulares de los derechos de propiedad industrial quedarán protegidos en su país y en los pertenecientes a la Unión (países contratantes del Convenio). Entre estas naciones son susceptibles de establecer vínculos por estar involucradas en la propiedad industrial.

El numeral 1 del Artículo 2 del Convenio de París prescribe que "Los nacionales de cada uno de los países de la Unión gozarán en todos los demás países de la Unión, en lo que se refiere a la protección de la propiedad industrial, de las ventajas que las leyes respectivas concedan actualmente o en el 
futuro a sus nacionales, todo ello sin perjuicio de los derechos especialmente previstos por el presente Convenio. En consecuencia, aquéllos tendrán la misma protección que éstos y el mismo recurso legal contra cualquier ataque a sus derechos, siempre y cuando cumplan las condiciones y formalidades impuestas a los nacionales.

El 14 de julio de 1967, se firma en Estocolmo (Suecia) el Convenio que establece la Organización Mundial de la Propiedad Intelectual (OMPI), (WIPO por sus siglas en inglés) y enmendado en el mismo lugar el 28 de septiembre de 1979. El Artículo 3 dictamina que las funciones del Convenio serán "fomentar la protección de la propiedad intelectual en todo el mundo mediante la cooperación de los Estados, en colaboración, cuando así proceda, con cualquier otra organización internacional", al igual que mantener la colaboración administrativa entre los diferentes tratados.

Este Convenio crea la Organización Mundial de la Propiedad Intelectual con el objeto de articular y administrar eficazmente la protección derivada de los convenios y arreglos legislativos internacionales que hasta ese momento protegían la propiedad industrial y los derechos de autor. El numeral 2 del Artículo 4 prescribe que el Convenio se encargará de los "servicios administrativos de la Unión de París" y de las uniones parecidas relacionadas con el Convenio de París. Colombia mediante la Ley 46 de 1979, se adhesiona al Convenio.

La Ley 410 de 1971, más conocida como el Código de Comercio, regulaba primigeniamente en el Título II lo relativo a la propiedad industrial. Posteriormente este contenido fue modificado por la Decisión 85 del Acuerdo de Cartagena -que el 26 de mayo de 1969, en Bogotá dio paso a la integración andina entre Colombia, Perú, Bolivia y Ecuador-, que se llamó "Reglamento para la aplicación de las normas de la propiedad industrial” del 5 de junio de 1974. Después, la Decisión 311 del 12 de diciembre de 1991, la Decisión 313 del 14 de febrero de 1992 vinieron a modificar la Decisión 85. El 29 de octubre de 1993, entra a regir la Decisión 391. Finalmente la Decisión 486 del 2000 que es la que está en vigencia en la actualidad, reglamentada parcialmente por el Decreto 2591 de 2000 y la Circular Única (10) de 2001 de la Superintendencia de Industria y Comercio. (Leal, 2012)

La Constitución Política de 1991, a través del Artículo 9 reconoce la importancia de las relaciones exteriores de Colombia y los tratados resultantes de ella. Es decir, los tratados firmados por Colombia antes de la entrada en vigencia de la Carta Magna, hacen parte del bloque de constitucionalidad y por ende, son de completa obligatoriedad y cumplimiento -aquí están incluidos los de propiedad industrial-; aunado a que el Artículo 61 de la Constitución expresamente protege la propiedad intelectual por el “tiempo y las formalidades que establece la ley.

La Decisión 486 del 2000, establece un marco legal de la propiedad industrial, para los países que integran la Comunidad Andina, a saber, Colombia, Perú, Bolivia, Ecuador y otrora Venezuela. Este instrumento jurídico al igual que el Convenio de París, define cada uno de los derechos de la propiedad industrial, sus requisitos constitutivos. También creó un proceso judicial uniforme que permite las acciones simultáneas en contra de violaciones a los derechos de la propiedad industrial, medidas cautelares, sanciones comerciales para los infractores, prohibiciones de importación y exportación, la acción reivindicatoria por daños y perjuicios, entre otras medidas. 
Todas las anteriores normatividades tanto las internacionales como las andinas, dan cuenta de las patentes. Adjunto a aquellas, existen instrumentos como el Tratado de Cooperación en materia de patentes (PCT) y el reglamento del mismo, que fue adoptado por la legislación colombiana por medio de la Ley 463 de 1998. El Tratado de Budapest sobre el reconocimiento internacional del depósito de microorganismos a los fines del procedimiento en materia de patentes introducido por la Ley 1515 del 2012.

\section{LAS PATENTES}

La patente es un privilegio que otorga el Estado al inventor como reconocimiento de la invención y los esfuerzos realizados para llegar a las invenciones que aportan una solución técnica a la humanidad. Dicho privilegio consiste en el derecho a explotar exclusivamente el invento por un tiempo determinado.

La Decisión 486 del 2000, norma reguladora del tema en Colombia establece que son 20 años lo que duran las patentes de invención, ya sea explotándolo directamente o dando licencias o transfiriendo los derechos patrimoniales.

La Superintendencia de Industria y Comercio, entidad adscrita al Ministerio de Industria y Comercio y autoridad ante la cual se realizan los trámites de propiedad industrial en el país, y por ende las patentes, dice que "son susceptibles de protección los inventos que sean productos, procedimientos, métodos de fabricación, máquinas o aparatos que se obtengan de ellas" (Superintendencia de Industria y Comercio, 2014). En Colombia existen patentes de invención y patentes de modelo de utilidad.

Para que un invento sea reconocido como patente, la Decisión 486 del 2000 en el artículo 14 dice que deben ser "nuevas, tener nivel inventivo y susceptibles de aplicación industrial". El Artículo 16 expresa que se considerará una invención nueva cuando no esté en el estado de la técnica que "comprenderá todo lo que haya sido accesible al público por una descripción escrita u oral, utilización, comercialización o cualquier otro medio antes de la fecha de presentación de la solicitud de patente o, en su caso, de la prioridad reconocida.

También se considerará novedosa una invención si no ha sido presentada, explotada o publicada antes de la presentación de la solicitud o de la prioridad que da la Decisión Andina. El llamado requisito de originalidad, como lo llaman los teóricos. La excepción a esta regla son los actos de divulgación de mala fe, las exposiciones públicamente reconocidas en cualquier país de la Comunidad Andina o para fines académicos e investigativos.

En segundo lugar debe tener un nivel inventivo, es decir, que no sea un proceso o producto obvio para alguien experto en la materia. Finalmente, aquello que se inventa, que es por lo cual se presenta la solicitud de patente, debe poderse aplicar en cualquier industria, y producir un efecto técnico. Cabe anotar que este requisito está presente en el derecho latino, más no en el anglosajón, al que pertenece Estados Unidos. 
La protección sobre los derechos económicos del invento o el modelo de utilidad solo serán una realidad cuando la patente haya sido otorgada. Sin embargo, una vez esto sea un hecho, se protegerá desde la fecha de presentación de solicitud de la patente. En Colombia la fecha de protección de las patentes son de 20 años contados desde la fecha de presentación de la solicitud.

Para solicitar una patente en Colombia, la Superintendencia de Industria y Comercio prevé un proceso especial. Luego de la radicación de la solicitud, la entidad realiza un examen de forma para ver si la solicitud cumple los requerimientos técnicos, en especial los que están en los Artículos 26 y 27 de la Decisión 486. Se da un período para corregir los vacíos o yerros que se encuentren. Posteriormente si el examen de forma resulta exitoso, se publica en la Gaceta de la Propiedad Industrial la solicitud para enterar a la sociedad y para permitir la presentación de oposiciones al proceso, las cuáles deben ser contestadas por el interesado.

Dentro de los seis meses desde la fecha en la cual la solicitud es publicada, se debe pedir el examen de patentabilidad -so pena de ser tenida como abandonada- que es aquel donde los funcionarios competentes determinan si el invento o el modelo de utilidad puede ser protegido mediante patente. Si la patente es concedida, se le notifica al solicitante mediante un acto administrativo. A partir de ese momento, el dueño de la patente debe estar pendiente de pagar las tasas de mantenimiento, que vienen previstas en las circulares anuales de la Superintendencia de Industria y Comercio que establecen las tasas de los procedimientos de propiedad industrial. (Superintendencia de Industria y Comercio, 2014)

\section{a. LA PATENTE FARMACÉUTICA}

Las patentes farmacéuticas son aquellas protecciones que le prodigan los Estados a los inventos y productos derivados del sector empresarial que se encarga de la fabricación y comercialización de productos químicos medicinales para el tratamiento y la prevención de enfermedades.

Estos productos químicos medicinales, se basan en el aislamiento de moléculas químicas, que luego de ser individualizadas y tratadas químicamente puedan ser utilizadas con fines terapéuticos, paliativos o curativos. Esto es lo que se conoce como principio activo. Los principios activos son aquellos componentes de los cuáles se derivan los efectos farmacológicos. Una vez purificado químicamente, recibe el nombre de fármaco.

Existen principios activos orgánicos e inorgánicos. Los inorgánicos son aquellos que vienen de una molécula, un óxido metálico, un óxido de zinc, óxido de hierro, un óxido ácido, un hidróxido, un ácido, una sal. Los orgánicos son los que provienen de "la biosíntesis de la planta y puede ser una sustancia simple o compleja dependiendo de la ruta metabólica que haya dado su resultado a partir de la fotosíntesis. Puede estar formado por sustancias de reserva de la plata (carbohidratos), cumplir funciones específicas dentro del funcionamiento orgánico vegetal (enzimas) o ser producto final que se excreta por algunos órganos específicos como los frutos o las flores (aceites esenciales) o por zonas específicas como la epidermis (gomas y resinas) (ver mayor información en el web site: http://www.plantas-medicinal-farmacognosia.com) 
Una de las innovaciones jurídicas que trajeron los ADPIC, que es de obligatorio cumplimiento para todos los países adscritos a la Organización Mundial del Comercio, fue la abolición de la prohibición de patentar medicamentos y alimentos. Los productos farmacéuticos solo podían ser patentados en virtud del procedimiento para llegar a ellos, pero no el producto terminado como tal. Se consideraba una superposición válida de la salud pública sobre los intereses comerciales. Se trataba de la consideración, así como lo enuncia Baylos (1978) citado por Uribe (2005) "no es conveniente conceder a nadie el monopolio de la producción de remedios para la salud humana o animal...". Los ADPIC fueron prácticamente replicados por la Decisión 486 del 2000 de la Comunidad Andina de Naciones, que también le dio vía libre a las patentes de medicamentos, e incluso eliminó la excepción que traía la Decisión 344 de 1993, que excluía de patentabilidad a los productos farmacéuticos que fueran calificados como medicamentos esenciales por la Organización Mundial de la Salud. Esta última excepción también era recogida por el Código de Comercio de 1971 en el Artículo 13 y que fue derogado en la parte correspondiente a la propiedad industrial por la Decisión Andina del 2000.

La Decisión 486 del 2000 -influencia por los ADPIC- también alargó el tiempo de concesión de las patentes, al colocarlo en 20 años. Esta disposición cambió lo establecido en la Decisión 85 de 1978 de la Comisión Económica para América Latina y el Caribe (CEPAL) que reconocía un término máximo de duración de 10 años -después de 5 prorrogables-. El Código de Comercio Colombiano prescribía un término de 8 años más 4 prorrogables. La prorrogabilidad en ambos corpus normativos dependía de la demostración de la efectiva explotación de la patente por parte del titular del derecho. Aspecto que también fue sustancialmente cambiado por los ADPIC y por la Decisión 486, pues asimilan explotación a importación. El privilegio de exclusividad deja de ser un estímulo a la innovación para convertirse en un abusivo monopolio de comercialización, con base en una tecnología obsoleta, que siendo conocida por los técnicos en la materia, no puede utilizarse por estar vigente la patente. (Mario Uribe Arbeláez ,2005)

\section{b. CONOCIMIENTOS TRADICIONALES Y PATENTES}

De la Cruz (2001), en su texto Biodiversidad, Derechos Colectivos y Régimen sui generis de Propiedad Intelectual define los conocimientos tradicionales como "aquellos que poseen los pueblos indígenas, afroamericanos, y comunidades locales trasmitidos de generación en generación, habitualmente de manera oral y desarrollados al margen del sistema de educación formal ...Es decir se tratan de conocimientos dinámicos que se encuentran en constante proceso de adaptación, basados en un cuerpo sólido de valores y bagajes artísticos profundamente enraizados en la vida cotidiana de los pueblos indígenas. Los conocimientos tradicionales no son estáticos, sino al contrario se encuentran en constante proceso de innovación y se adaptan a cambios dependiendo del medio en que interactúan...". (De la Cruz, 2001)

Los conocimientos tradicionales son cuerpos cognoscitivos que se desprenden de la cosmovisión de los pueblos tradicionales. No obedecen a las reglas de la epistemología occidental, ni encajan en la racionalidad convencional. No pueden verse como células desperdigadas del entorno en el que surgen, sino que deben ser valorados como un tono indivisible. Este es el fundamento de lo que los 
tratadistas de la Propiedad Intelectual han Ilamado Derechos Colectivos de la Propiedad Intelectual.

El antropólogo estadounidense Darrel Posey en su obra International Agreement and Intellectual Property Rights for Indigenous People: a sourcebook enunció las 9 categorías en las que se enmarcan los conocimientos tradicionales, que son las siguientes: Posesiones sagradas; conocimientos de uso, previo y potencial de plantas, suelos y minerales conocidos por un grupo cultural; conocimiento, preparación, proceso y almacenamiento de especies útiles; fórmulas que involucran más de un ingrediente; conocimientos selectivos de una especie; conservación de ecosistemas; recursos biogenéticos; herencias culturales y sistemas de clasificación de conocimientos. (Posey, 1994)

Es importante recalcar que los conocimientos tradicionales, comprendida esta noción de una manera íntegra de acuerdo a lo que vimos en el párrafo anterior, son plenamente protegidos por los instrumentos internacionales ratificados por Colombia y que son de obligatorio cumplimiento. Sin lugar a dudas, el principal es el ADPIC (Acuerdo sobre los aspectos de Propiedad Intelectual relacionados con el Comercio); en su Artículo 27b excluyó de patentabilidad las plantas animales, los microorganismos, los procesos esencialmente biológicos o no biológicos. Establece que la protección de las especies vegetales, puede darse, ya sea por patentes o por protección sui generis o la mezcla de ambos. El Convenio de la Diversidad Biológica, en el Artículo 8, literal j, ordena que los países contratantes deben respetar, preservar y mantener los conocimientos, las innovaciones y las prácticas de las comunidades indígenas y locales, que tengan estilos de vida tradicionales, acordes con la diversidad biológica y que deben velar por el reparto equitativo de estos beneficios. Estas prescripciones están cimentadas por lo dicho en el Artículo 15 del Pacto de los Derechos Civiles y Políticos que reconoce el derecho que tienen los autores de que sus intereses morales y materiales derivados de sus producciones literarias y artísticas sean protegidos. Entonces, las comunidades tradicionales, entrarían dentro de esta categoría de autor, que si bien, a veces raya con su cosmogonía, en términos prácticos y frente a la avanzada de entes corporativos inescrupulosos, es de gran utilidad.

El tema de la relación de los conocimientos tradicionales y la propiedad intelectual es complejo. Ontológicamente hay una discrepancia, especialmente a la luz de los derechos humanos, donde la protección que debida a los pueblos tradicionales raya con un sistema de propiedad privada para sus tradiciones milenarias. Los más osados tratadistas, aducen que el derecho de la propiedad intelectual es insuficiente para tratar los conocimientos tradicionales y que se deberían pensar otras nociones jurídicas igual de válidas. Rosángela Calle Vázquez en su texto "El conocimiento tradicional y la propiedad intelectual" afirma que:

Los conceptos "Derechos Comunitarios Intelectuales"; "Derechos sobre Recursos Tradicionales" y los Modelos de provisiones para su protección, son alternativas para establecer una figura sui generis de propiedad intelectual tradicional o comunitaria que previenen su privatización, además incorporan el contenido de derechos como la autodeterminación incluyendo derechos humanos y territorio; cubre el amplio campo de protección como el conocimiento, los recursos biogenéticos, la propiedad cultural, el folclor y el paisaje. (Calle, 1999) 
Vale resaltar que hay una protección a los conocimientos tradicionales en la Constitución Política de 1991, en el Artículo 42 cuando dice que el patrimonio arqueológico y otros bienes culturales son inalienables, inembargables e imprescriptibles. La medicina tradicional de una comunidad afroamericana hace parte de esos bienes culturales constitucionalmente protegidos.

\section{c. PATENTES EN EL TRATADO DE LIBRE COMERCIO CON ESTADOS UNIDOS}

Los TLC son acuerdos regionales, comerciales o bilaterales que buscan expandir el mercado de bienes y servicios de los países participantes. Básicamente, rebajan y/o desgravan los aranceles y se realizan otros acuerdos de servicios o temas adjuntos. Estos tratados son regulados por la Organización Mundial de Comercio (OMC) de la que Colombia hace parte.

El Acuerdo de Promoción Comercial entre Colombia y Estados Unidos, mejor conocido como TLC, sus cartas adjuntas y sus entendimientos fueron firmados el 22 de noviembre del 2006 en la ciudad de Washington. La ley colombiana que incorporó el tratado al corpus legislativo fue la 1143 del 2007 y la Sentencia C-750 del 2008 lo declaró exequible. El Protocolo Modificatorio del tratado entró a la legislación colombiana bajo la Ley 1166 del 2007 y declarado exequible por la sentencia C-751 del 2008. El 12 de octubre del 2011 fue aprobado por el Congreso norteamericano y fue sancionado por el presidente Barak Obama el 21 de octubre del mismo año. En la pasada Cumbre de las Américas que se llevó a cabo en Cartagena en abril del 2011, se realizó el canje de notas y el día 15 de mayo del 2012, cuando se promulgó el "Acuerdo de Promoción Comercial entre la República de Colombia y los Estados Unidos de América”, sus Cartas adjuntas y sus entendimientos, entró en vigencia.

El Capítulo XVI del Tratado de Libre Comercio, establece lo pertinente respecto a la propiedad intelectual. Específicamente el Artículo 16.9 regula lo referente a las patentes. En el inciso 1 especifica que se patentará en todos los campos de la tecnología, que deben tener capacidad inventiva y aplicación industrial. En el Inciso 2, se establece expresamente que a pesar de lo señalado en el ADPIC, Artículos 27.2 y 27.3 -estos artículos prohíben la patentabilidad de las plantas y los animales con excepción de los microorganismos dado lo expresado en el Párrafo 1 se podrán patentar plantas y esta debe mantenerse a toda costa. En el Inciso 3 se dice que serán excepcionales las razones por las cuáles se puedan limitar los derechos que confiere una patente y por ningún motivo, pueden ir en contra de la normal explotación de la patente, ni perjudicar los derechos del titular de la patente y teniendo en cuenta los legítimos derechos de los titulares de las patentes y sin perjudicar a los terceros. En el Entendimiento sobre Conocimientos Tradicionales se deja a la voluntad de los "contratantes" -si es que a las comunidades tradicionales podemos enmarcarlas plenamente en el término- el consentimiento informado y la distribución equitativa de beneficios, hecho que ahonda aún más el desigualdad trato y el potencial riesgo de ilegal patentamiento.

\section{d. MEDICINA TRADICIONAL DE SAN BASILIO DE PALENQUE}

La medicina tradicional palenquera es sumamente rica y diversa. Está compuesta por tres elementos: plantas, rezos y animales. Sus conocimientos se dividen en altos, medios y bajos, teniendo en cuenta el nivel de experiencia y sabiduría del médico tradicional y también si es 
maestro o aprendiz. A diferencia de la medicina occidental, la aptitud para ejercer la profesión de médico no está determinada por un diploma que pruebe habilidades cognitivas. Ellos, parten de una consideración subjetiva de la persona, de la "bondad" o "maldad" de su espíritu y por eso son enfáticos al afirmar que no todos pueden ser médicos tradicionales -lo que coadyuva el carácter ancestral y sumamente espiritual de sus conocimientos-. Ellos tratan las enfermedades somáticas y las espirituales. El caso que traemos a colación es el tratamiento de una enfermedad somática.

Para el caso preciso de este artículo, tomaremos el caso de una receta específica, utilizada por los palenqueros, que ha pasado de generación en generación y que potencialmente puede ser patentada por firmas farmacéuticas norteamericanas, dada la laxitud con que quedó redactado lo referente a la propiedad Intelectual en el TLC con Estados Unidos.

La receta es la fusión de la salvia, la cola de babilla y el cáñamo, que se usa para tratar las afecciones respiratorias, específicamente la gripe, también conocida como influenza. Esta fusión se le da al paciente tres veces al día, a través de un utensilio tradicional llamado "totuma" por un período de siete días. Luego de este período, el paciente presenta síntomas de clara recuperación.

La salvia es un arbusto que mide hasta medio metro de altura, con hojas verdes grisáceas y flores violetas, sagrada desde la Grecia Antigua, entre sus principales componentes químicos podemos citar la vitamina A, Vitamina $B$, bactericidas, potasio y enzimas ${ }^{4}$. El cáñamo es una variación del cannabis que contiene menos de 0,3 de THC (tetrahidrocannabidol) que es cultivado en América Central y Sudamérica desde tiempos inmemoriales ${ }^{5}$. La cola de babilla es la parte inferior de un reptil de humedales del mismo nombre, conocido también como caimán de anteojos o baba, que es originario de la parte norte de América del Sur, Centroamérica y algunas partes del Caribe ${ }^{6}$.

\section{CONCLUSIONES}

La firma del Tratado de Libre Comercio con Estados Unidos es un hecho que sobrepasa lo meramente formal. Con esa firma plasmada en la Cumbre de las Américas en Cartagena, se vinieron una serie de consecuencias controversiales en lo que respecta a la propiedad intelectual. En el artículo se demostró que tal como quedó redactado el TLC con Estados Unidos, se pasó por encima del ADPIC y del Convenio de la Diversidad Biológica de 1992 y que se abrió la posibilidad del patentamiento de plantas, además de que se da una prevalencia de los intereses comerciales sobre los ecológicos y los que tienen que ver con el desarrollo sostenible.

Es un hecho cierto e irrefutable que los mecanismos de propiedad intelectual, y en este caso específico, de propiedad industrial no responden a la cosmovisión palenquera. Ellos, circunscritos a lo que Mario Uribe Arbeláez ha llamado los derechos colectivos de la propiedad intelectual, no

\footnotetext{
${ }^{4}$ Ver más en Tomado de http://www.lineaysalud.com/medicina-alternativa/339-la-salvia-complemento.html el 11 de agosto del 2013 a las 5:34 p.m.

${ }^{5}$ Ver más en Tomado de http://www.cannabiscollege.com/esindustrialhemp.html el 11 de agosto del 2013 a las 5:36 p.m.

${ }^{6}$ Ver más en Tomado de http://www.zoologicosantafe.com/reptiles-y-aves/caiman-babilla-esp-common-caiman-spectacled-caimaneng el 11 de agosto del 2013 a las 5:38 p.m.
} 
consideran la propiedad privada sobre la farmacopea tradicional. Todo es trasmitido de generación en generación y no conciben el lucro individual para uno de ellos, para conocimientos que son de siglos.

En todo caso, para efectos estratégicos, recomendamos que el Consejo Comunitario Mankamana inicie un trámite de solicitud de patente de producto ante la Superintendencia de Industria y Comercio de Colombia -entidad del orden nacional que se encarga de registrar los derechos de la propiedad industrial- en aras de prevenir cualquier uso inadecuado que potencialmente puedan las hacer las firmas farmacéuticas norteamericanas sobre las plantas utilizadas en la medicina tradicional palenquera. En el ejemplo concreto, patentar el principio activo de la fusión de salvia, cáñamo y cola de babilla.

Este es un trámite que debe ser realizado con el acompañamiento del Ministerio de Cultura de Colombia y la Gobernación de Bolívar. Debe ser hecho a nombre del Concejo Comunitario y no de los médicos tradicionales, para reconocer que estos no son conocimientos inventados por algunos de ellos, sino que son una epistemología farmacológica colectiva, digna de ser protegida, no solo frente al Tratado de Libre Comercio con Estados Unidos, sino frente a los otros TLC que ha firmado Colombia en el presente gobierno.

\section{REFERENCIAS BIBLIOGRÁFICAS}

AGUIRRE, J. y GARZA, R. (2005) “Propiedad industrial, certidumbre jurídica y competitividad”. Monterrey. Fondo Editorial Nuevo León. México. Fondo Editorial Universidad de Monterrey.

CALLE, R. (1999) "El conocimiento tradicional y la propiedad intelectual. Biocomercio: Estrategias para el desarrollo sostenible en Colombia". En: Revista Gestión y Ambiente. Número del 2 de agosto de 1999 página 270 -273. Colombia. Universidad Nacional de Colombia y el Instituto de Estudios Ambientales IDEA.

CRUZ, R. (2001) "Protección a los conocimientos tradicionales". Isla Margarita, Venezuela. Cuarto Taller Acceso de recursos genéticos, conocimientos y prácticas tradicionales y distribución de beneficios.

INSTITUTO ALEXANDER VON HUMBOLT. (2000) "Protección del conocimiento tradicional. Elementos conceptuales para una propuesta de reglamentación". Bogotá.

COLECTIVO POR UNA ALTERNATIVA A LA BIOPIRATERÍA (2010) “La biopiratería: entender, resistir, actuar". Guía de información y de movilización frente a la apropiación ilegítima de los recursos biológicos y de los conocimientos tradicionales.

LEAL, H. (2012) “Código de Comercio de Colombia”. Bogotá: Editorial Leyer.

MINISTERIO DE CULTURA \& INSTITUTITO COLOMBIANO DE ANTROPOLOGÍA E HISTORIA (2002) "Palenque de San Basilio: Obra maestra del Patrimonio Intangible de la Humanidad". Dossier de Candidatura ante la Organización de las Naciones Unidas para la Educación, la Ciencia y la Cultura. Bogotá. 
POSEY, D. (1994) "International Agreement and Intellectual Property Rights for Indigenous People: a sourcebook". Society for Aplied Anthropology. Oklahoma City.

ROBLEDO, P. F. (2006) "Los derechos del obtentor de variedades vegetales". Universidad Externado de Colombia. Bogotá: Centro de Estudios de la Propiedad Intelectual.

SERCOVICH, F.C. (2008) "Tratados de libre comercio, derechos de propiedad intelectual y brechas del desarrollo: dimensiones de política desde una perspectiva latinoamericana". Ciudad de México. Unidad de Comercio Internacional e Industria. Sede Subregional de la CEPAL. 